Rev. Asoc. Esp. Neuropsiq. 2020; 40(I 37): 2 I 5-220

DOI: I0.432 I/SO2 I I-57352020000IO00I 3

\title{
Hachís: entre la locura y el remedio
}

Hash: between madness and cure

Olga Villasante Armas

Hospital Universitario Severo Ochoa, Leganés, Madrid.

Correspondencia: Olga.villasante@salud.madrid.org

Jacques-Joseph MOREAU (DE TOURS) (2019), Del hachís y de la alienación mental, Madrid, AEN. ISBN: 978-84-9528791-5, 246 páginas.

$\mathrm{L}$ A TRADUCCIÓn DE DEL HACHÍS Y DE LA ALIENACIÓN MENTAL responde, sin duda, a una deuda que la psiquiatría española debía a Jacques-Joseph Moreau (18041884), más conocido por Moreau de Tours, en referencia al lugar donde estudió el bachillerato y comenzó los estudios de Medicina. El profesor de la Universitat de València e investigador del Instituto Interuniversitario de Historia de la Medicina y de la Ciencia López Piñero Enric Novella, con la inestimable colaboración de Silvia Fervenza y Marisa Cuñat, han editado y traducido esta obra, por primera vez, al español. De este modo, la Colección de Libros de Historia de la Asociación Española de Neuropsiquiatría (AEN), que comenzó su andadura con la renombrada Anatomía de la melancolía de Robert Burton en 1997 (1), se enriquece con este título capital de la psiquiatría francesa que constituye el volumen 30.

La traducción está precedida por una ilustrativa introducción de José María Villagrán en la que esboza la biografía, obra y trayectoria profesional del alienista francés, cuyo conocimiento enriquece la lectura de este fascinante libro. Los viajes de Moreau a Oriente Medio, sin duda, están en la raíz de este texto del discípulo de Esquirol (1772-1840), quien en 1836 acompañó a un acaudalado paciente de su maestro a Malta, Turquía (Esmirna y Constantinopla) y El Cairo. Además de interesarse por la atención a los pacientes psiquiátricos, que conoció visitando diversas 
instituciones, observó los efectos fisiológicos y psicológicos del estramonio y el cannabis, plasmados en Recherches sur les aliénés en Orient (2).

En un breve apunte histórico que corresponde a la primera parte del libro, Moreau se remontaba a la Antigüedad Clásica, describiendo que el cannabis indica era el Nepenthes de Homero (el brebaje que Helena hacía beber a Telémaco, en casa de Menelao, para hacerle olvidar sus males). Reivindica, además, la figura de Louis Rémy Aubert-Roche (1818 - 1874) como el primer francés que llamó la atención sobre los efectos del hachís con su obra De la peste ou typhus d'Orient: Documens et observations recueillis pendant les années 1834 à 1838, en Egypte, en Arabie, sur la Mer Rouge, en Abyssinie à Smyrne et à Constantinople (3). Curiosamente, Aubert-Roche había utilizado el hachís para tratar la peste y describió siete curaciones de once casos graves, sugiriendo que podría utilizarse en otros campos de la medicina. En el mundo anglosajón, no podemos olvidar la referencia a William Brooke O'Shaughnessy (1809-1889), que había publicado, solo un año antes, el tratado On the preparation of the Indian hemp or gunja (4).

Antes de detallar los efectos del hachís, Moreau describía algunas características botánicas del cánamo y algunas preparaciones del cannabis indica (una planta común en la India y Asia Meridional similar al cáñamo europeo). El dawamesc, la forma más común entre los árabes, fue utilizada por Moreau y su entorno para valorar y describir la influencia que ejercía sobre las facultades intelectuales. Se trataba de un extracto graso que, después de un proceso (hervir las hojas y las flores de la planta en agua, añadir mantequilla fresca, reducción por evaporación y conversión en jarabe...), se convertía en un electuario, a modo de preparación medicinal de consistencia pastosa que contenía miel, azúcar o frutos secos para dulcificar el sabor.

En la segunda parte del libro, que constituye prácticamente todo el cuerpo del trabajo, el autor justifica el consumo de hachís como una vía, quizá la más genuina, para explorar la patología mental a través de la acción del dawamesc sobre las facultades mentales. Define el "hecho primordial" como el hecho primitivo generador del que se derivan todos los síntomas de la locura, defendiendo incluso una identidad estricta entre los fenómenos del sueño y la locura. Se ha postulado que estas originales propuestas del francés inspiraron a autores tan relevantes como Gaëtan Gatian de Clérambault (1872-1934) o Henri Ey (1900-1977), considerando a este último el pionero de la concepción órgano-dinámica de la psiquiatría (5).

Las investigaciones de Moreau sobre los efectos del hachís no se pueden separar de la fundación, en 1844, del Club des Hashischins', de apenas cuatro años

\footnotetext{
${ }^{1}$ El término árabe 'ḥaššǎššn', que significa 'adicto al cáñamo indio/hachís', es considerado el origen etimológico de la palabra "asesino". Entre los siglos VIII y XIV, daba nombre a los miembros de una secta militar chiita-ismaelita (los nizaríes) del Medio Oriente, adictos al hachís, cuya actividad era matar a reyes o dirigentes religiosos, militares y políticos. El término se ha adaptado a diferentes lenguas: 'assassinnus' (latín), 'assassin' (inglés), 'assassin'(francés), 'Assassin' (alemán), assassino' (italiano y portugués).
} 
de existencia (1844-1849). Este efímero club parisino que se reunía en el hotel de Lauzun, sito en la Île de Saint-Louis, fue promovido por el dramaturgo, novelista y poeta Théophile Gautier (1811-1872) y el pintor Fernand Boissard (1813-1866), además del alienista. En las reuniones mensuales instaba a un grupo, en el que también estuvieron Gérard de Nerval (1808-1855), Charles Baudelaire (1821-1867), Eugène Delacroix (1798-1863), Alexandre Dumas (1802-1870), Honoré de Balzac (1799-1850) o Victor Hugo (1802-1885), al consumo de hachís. No exento de críticas por cuestiones éticas, el discípulo de Esquirol trataba de conocer la esencia de la psicosis mientras alumnos invitados anotaban las conductas y comentarios de la élite parisina que tomaba dawamesc (6).

Moreau, convencido del valor del hachís como un poderoso medio para la exploración de la patogenia mental, describía los efectos físicos a medida que se administraban dosis crecientes de este. Describía ocho fenómenos psicológicos, completamente análogos entre los consumidores y los alienados: sentimiento de felicidad, excitación y disociación de ideas, apreciación errónea del tiempo y espacio, hipersensibilidad auditiva e influencia de la música, ideas fijas y convicciones delirantes, lesiones de los afectos, impulsos irresistibles y, por último, ilusiones y alucinaciones. A partir de un cuarto de dicha nuez (la nuez pesaba en torno a 30 gramos), se podían observar la alegría o risa tonta o, incluso, pasar desapercibido porque el efecto se limitara a un sentimiento de bienestar y dulce expansión $\left(7\right.$, p. $\left.67^{2}\right)$. El segundo fenómeno -el proceso de disociación, desagregación y disolución de las ideas- fue considerado el hecho primordial (fait primordial) o la lesión fundamental del desorden del intelecto que generaría todos los síntomas y formas de locura (7, p. 219). El alienista consideraba que la acción del hachís conducía a debilitar nuestra voluntad y el poder intelectual que dominaba las ideas, las asociaba y las relacionaba unas con otras, predominando la memoria y la imaginación (según refería, la voluntad nos mantiene en el presente, con la memoria vivimos en el pasado y con la imaginación, en el futuro). Los diferentes fenómenos psicopatológicos son ilustrados por Moreau con casos más o menos extensos, algunos incluso de sus amigos, como aquel que describía la gran distorsión del tiempo experimentada por Gautier tras el consumo de hachís. El literato francés también fue el protagonista de una hipersensibilidad auditiva asociada a la música: "Mi oído se había desarrollado prodigiosamente, oía el sonido de los colores; sonidos verdes, rojos, azules, amarillos, me alcanzaban por medio de ondas perfectamente diferenciadas..." (7, p. 78). El mismo Moreau relataba hasta qué punto le impresionaba la música, detallando una escena en la que, con una dosis elevada de hachís y rodeado de unos amigos íntimos, escuchaba un vals de Weber. La tristeza del vals le llevo a una sombra melancólica, desbordando en sollozos y, poco después, la oración de Moisés de la ópera le ayudó a calmar la terrible pesadilla.

\footnotetext{
${ }^{2}$ El número de página corresponde a la edición en español, que aquí se reseña.
} 
De todos modos, el consumo de hachís no siempre generaba la aparición de estos ocho fenómenos psicopatológicos y Moreau apuntaba que el quinto fenómeno -ideas fijas, convicciones delirantes- era una lesión intelectual que solo se experimentaba con dosis elevadas de cánamo. De hecho, refiriéndose a sí mismo, reconocía que esta lesión, típica de los monomaniacos, solo la había experimentado una vez, en 1841. Junto a las convicciones delirantes (quinto fenómeno), las ilusiones y alucinaciones (el octavo y último fenómeno) fueron las que acapararon más atención del alienista francés, quien citaba a Esquirol como el primero en realizar un estudio serio y profundo de las alucinaciones. A pesar de la influencia esquiroliana, casi desde el comienzo de la carrera, su discípulo defendió la concepción somática de la locura y la "excitación" como causa esencial de procesos mentales como la disociación, la desagregación y la disolución de las ideas.

Probablemente es en el segundo capítulo donde más se aprecia el organicismo que distinguió a Moreau de gran parte de sus compatriotas, ya que en este apartado detallaba las condiciones fisiológicas y patológicas que favorecían el desarrollo de las alucinaciones. Defendía que la excitación, asimismo, era el origen de las alucinaciones, síntomas que ya habían captado su atención unos años antes (8). Enumeraba algunas de las sustancias que, a través de sus propiedades tóxicas, podían generar una excitación y secundariamente una alteración cerebral similar a los fenómenos del delirio, como el óxido nitroso, el opio, los licores alcohólicos o sustancias narcóticas. Entre estas, destacaba el estramonio o datura stramonium, cuyas propiedades psicoactivas ya eran conocidas desde tiempos de Dioscórides (8), la belladona (droga de las brujas), el beleño y el acónito (Beleño negro o hierba loca -hyosciamus niger-), utilizadas por hechiceros para provocar alucinaciones. Consideraba que esos estados intermedios entre la vigilia y el sueño, los estados febriles, las convulsiones o privaciones como el hambre, la sed o el frío se podían acompañar de alucinaciones, invadiendo al individuo y conduciéndolo a un estado próximo a la locura.

En el capítulo tercero y cuarto de la segunda parte, se dedicó a recoger las opiniones de algunos autores marcando las diferencias con su propio maestro en relación al origen de las ilusiones/alucinaciones. La convicción del "hecho mórbido psicocerebral” le llevó a una dura pugna con François Leuret (1797-1851), el máximo exponente de la evolución negativa del tratamiento moral (9), quien atribuía el fenómeno de las alucinaciones a la memoria o la imaginación (locura moral). Pero no fue el único contemporáneo con quien disentía y Moreau rebatió las opiniones de Louis F. Lélut (1804-1877) o de Jules Baillarger (1806-1891), autor de Fragments pour servir à une histoire des hallucinations (10).

Por último, la tercera parte del libro es una breve alusión a la terapéutica en la que rescataba siete casos de internados en Bicêtre (manía furiosa, manía intermitente, agitación maniaca...) a los que administró hachís en estado puro (hasta 15 gr.) o 
dawamesc (hasta 30 gr.) con una taza de café. Si bien reconocía que la exigua muestra no podía fundamentar una conclusión precisa, paradójicamente aquellas sustancias que reproducían el delirio también lo podían calmar, actuando de profiláctico y combatiendo la excitación maniaca. Las convicciones de Moreau le llevaron, en sus ochenta años de experiencia como psiquiatra trabajando en Charenton, Bicêtre, la clínica en Ivry-Sur-Seine y la Salpêtrière (11), a utilizar como arsenal terapéutico no solo el hachís sino el cloroformo, la belladona, el sulfato de quinina o el bromuro de potasio, entre otras. De hecho, su interés en aspectos farmacológicos como las dosis o la toxicidad le convirtieron en un precursor de la psicofarmacología (12).

A mi modo de ver, estas son solo algunas pinceladas para leer esta revolucionaria obra que ofrece detalladas y ricas descripciones de una psicopatología sin duda aún vigente. Sus originales planteamientos apelan a la introspección como una fuente legítima para el conocimiento de la locura, a través de la experiencia propia (13). De hecho, Moreau consideraba el consumo de hachís la auténtica vía regia para recrear, aprehender y examinar la experiencia inefable de alucinaciones, disociación, convicciones delirantes u otros fenómenos patológicos. Invitamos a la lectura de esta obra capital del alienismo francés decimonónico, pues no se limita a consignar finísimas observaciones, sino que formula una doctrina sobre los fundamentos y la naturaleza de la alienación mental. Por otra parte, Moreau de Tours nos acerca, en Del hachis y de la alienación mental (1848), al ya viejo debate entre los desórdenes funcionales y las alteraciones psicocerebrales.

\section{Bibliografía}

(I) Burton R. Anatomía de la melancolía. Madrid: AEN, 1997.

(2) Moreau JJ. Recherches sur les aliénés en Orient. Ann. Méd. Psychol. 1843; 1(1): 103-132.

(3) Aubert-Roche LR. De la peste ou typhus d'Orient: Documens et observations recueillis pendant les années 1834 à 1838, en Egypte, en Arabie, sur la Mer Rouge, en Abyssinie à Smyrne et à Constantinople (1840). Adamant Media Corporation, 2002.

(4) O'Shaughnessy WB. On the preparation of the Indian hemp or gunja. 1839.

(5) Ey H. Jacques Joseph Moreau de Tours. Prefacio a la obra de J. J. Moreau de Tours, Du hachisch et de l'aliénation mentale. Paris: Ediciones Fortin, Masson, 1845. Disponible en: http://psychanalyse-paris.com/+-Jacques-Joseph-Moreau-de-Tours-+.html.

(6) Rahmani R, Pacheco L. Jacques Joseph Moreau de Tours, un pionero de la Psiquiatría Experimental. Lmentala 2017; 50: 1-9. Disponible en http://lmentala.net/ admin/archivosboletin/Moreau.pdf.

(7) Moreau JJ. Du hachisch et de l'aliénation mentale. Paris, 1845. Disponible en: http://gallica.bnf.fr/ark:/12148/bpt6k768978. 
(8) Moreau JJ. Mémoire sur le traitement des hallucinations par le Datura stramonium, Gazette Médicale de Paris 1841; 9(41): 641-647; 9(43):673-680.

(9) Huertas R. François Leuret: Terapia e intimidación moral. Estudio introductorio a Leuret, F. El tratamiento de la locura. Madrid: AEN, 2001.

(10) Baillarger J. Fragments pour servir à une histoire des hallucinations. Revue Médicale, $1842 ; 1: 5-20$.

(11) Renner C. À propos de Moreau de Tours et du haschisch. Histoire des Sciences Médicales 2012; 46(4). Disponible en: http://www.biusante.parisdescartes.fr/sfhm/ hsm/HSMx2012x046x004/HSMx2012x046x004x0367.pdf.

(12) Ledermann F. Pharmacie, médicaments et psychiatrie vers 1850: Le cas de Jacques-Joseph Moreau de Tours. Revue d'histoire de la pharmacie 1998 (76 e année); 276:67-76. Disponible en: http://www.persee.fr/doc/pharm_0035-2349_1988_ num_76_276_2933.

(13) Novella E. El discurso psicopatológico de la modernidad. Madrid: Libros de la catarata, 2018. 